\title{
Remodeling an infarcted heart: novel hybrid treatment with transmyocardial revascularization and stem cell therapy
}

\author{
Jessika Iwanski 1,2, Raymond K. Wong ${ }^{1}$, Douglas F. Larson², Alice S. Ferng ${ }^{2,3}$, Raymond B. Runyan ${ }^{4}$, \\ Steven Goldstein ${ }^{5}$ and Zain Khalpey $2,3,6,7^{*}$
}

\begin{abstract}
Transmyocardial revascularization (TMR) has emerged as an additional therapeutic option for patients suffering from diffuse coronary artery disease (CAD), providing immediate angina relief. Recent studies indicate that the volume of surgical cases being performed with TMR have been steadily rising, utilizing TMR as an adjunctive therapy. Therefore the purpose of this review is to provide an up-to-date appreciation of the current state of TMR and its future developmental directions on CAD treatment. The current potential of this therapy focuses on the implementation of stem cells, in order to create a synergistic angiogenic effect while increasing myocardial repair and regeneration. Although TMR procedures provide increased vascularization within the myocardium, patients suffering from ischemic cardiomyopathy may not benefit from angiogenesis alone. Therefore, the goal of introducing stem cells is to restore the functional state of a failing heart by providing these cells with a favorable microenvironment that will enhance stem cell engraftment.
\end{abstract}

Keywords: Laser therapy, Stem cell therapy, Transmyocardial revascularization, Myocardial infarction, Coronary artery disease, CABG, Angina

\section{Background}

A significant number of patients currently suffering from coronary artery disease (CAD) experience severe ischemia due to multi-vessel atherosclerotic obstruction, leading to heart failure and impaired myocardial function (Allen et al. 2008). Prophylaxis and treatment for this patient population involves drug therapy, percutaneous coronary interventions (PCI) and coronary artery bypass grafting (CABG) (Allen et al. 2008; Kim et al. 2002). A large portion of these patients suffer from refractory CAD not amenable to percutaneous or conventional surgical interventions (Andréll et al. 2011; Allen et al. 2008; Kim et al. 2002). For this patient population the extent of CAD is widespread and traditional revascularization

\footnotetext{
*Correspondence: zkhalpey@surgery.arizona.edu

2 Department of Surgery, Division of Cardiothoracic Surgery, University of Arizona College of Medicine, P.O. Box 245071, 1501N. Campbell Avenue, Tucson, AZ 85724-5071, USA

Full list of author information is available at the end of the article
}

alone is not sufficient to reinstate adequate flow through the coronary vessels. Transmyocardial revascularization (TMR) has emerged as an additional therapeutic option. It has been reported to provide symptomatic angina relief with improved quality of life, decreased cardiac events and decreased cardiac re-hospitalizations (Allen et al. 1999; Gowdak et al. 2008; Reyes et al. 2010; Tasse and Arora 2007).

Within the past decade, research has encompassed the use of stem cells in conjunction with TMR as a novel dual therapeutic option (Dallan et al. 2008; Patel et al. 2007; Spiegelstein et al. 2007; Shahzad et al. 2012). Even though TMR procedures may provide increased vascularization within the myocardium, patients suffering from ischemic cardiomyopathy with depressed ventricular function may not benefit from angiogenesis alone. Therefore, with the introduction of stem cells the goal is to restore the functional status of a failing heart by enhancing stem cell homing and engraftment. Due to the regenerative capabilities of stem cells, (Tavris et al. 2012; Samuels 
et al. 2004; Horvath 2008; Lindsay 2003) it is predicted that concomitant injection with TMR may produce a synergistic effect that will improve cardiac function by decreasing patient angina and aiding in myocardial recovery, repair and regeneration.

\section{Operative technique}

TMR therapy can be performed with or without adjunctive CABG or other surgical procedures and it can be utilized with or without cardiopulmonary bypass support. For stand-alone laser therapy, a left anterior thoracotomy is performed in the fifth intercostal space, allowing exposure of the pericardium and left ventricular epicardial surface (Fig. 1). Typically 20-40 channels are generated within the left ventricle, depending on the ischemic region and size of the patient heart. Channels are first employed on the inferior surface, moving towards the apex of the heart and subsequently on the lateral and anterior aspects of the epicardial surface (Frazier et al. 2004; Tavris et al. 2012) (Fig. 2).

Considering most TMR procedures are performed concomitantly with CABG (Tavris et al. 2012), a median sternotomy and $\mathrm{CPB}$ support can be utilized during adjunctive therapy (Fig. 3). Under these conditions,

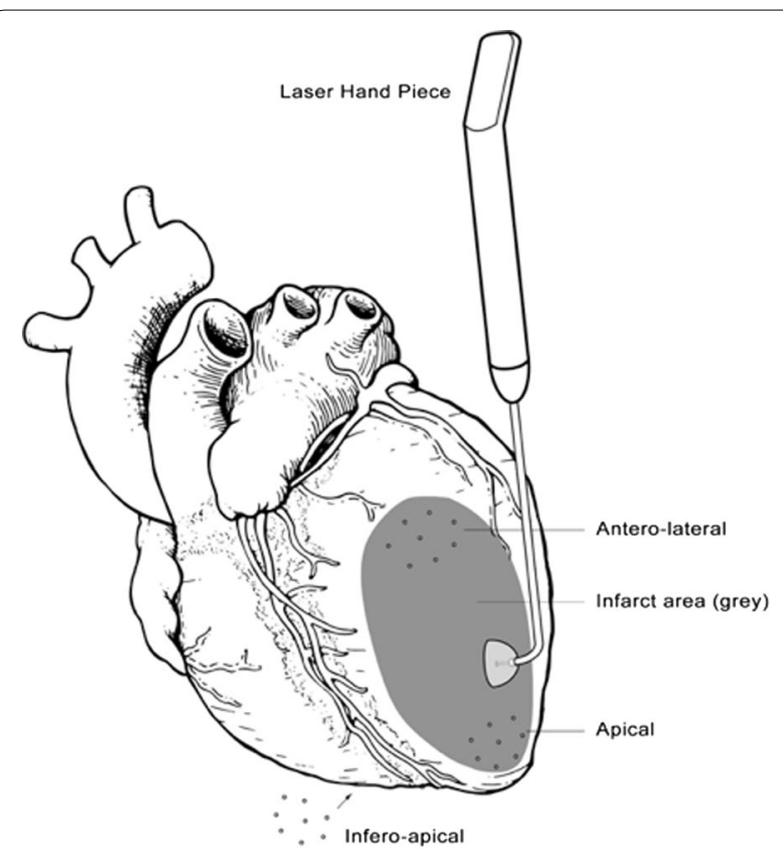

Fig. 1 Transmyocardial revascularization (TMR). TMR is performed on the heart by lasing channels in the myocardium, with an energy output of 7 W per laser pulse using the Ho:YAG fiber optic hand tool. The grey region seen on the heart represents an infarcted zone following ischemic damage. Depending on the ischemic region and size of the patient heart, a total of 20-40 channels are created using the TMR laser hand piece. Typically, channels are placed on the antero-lateral, apical, and infero-apical regions of the heart

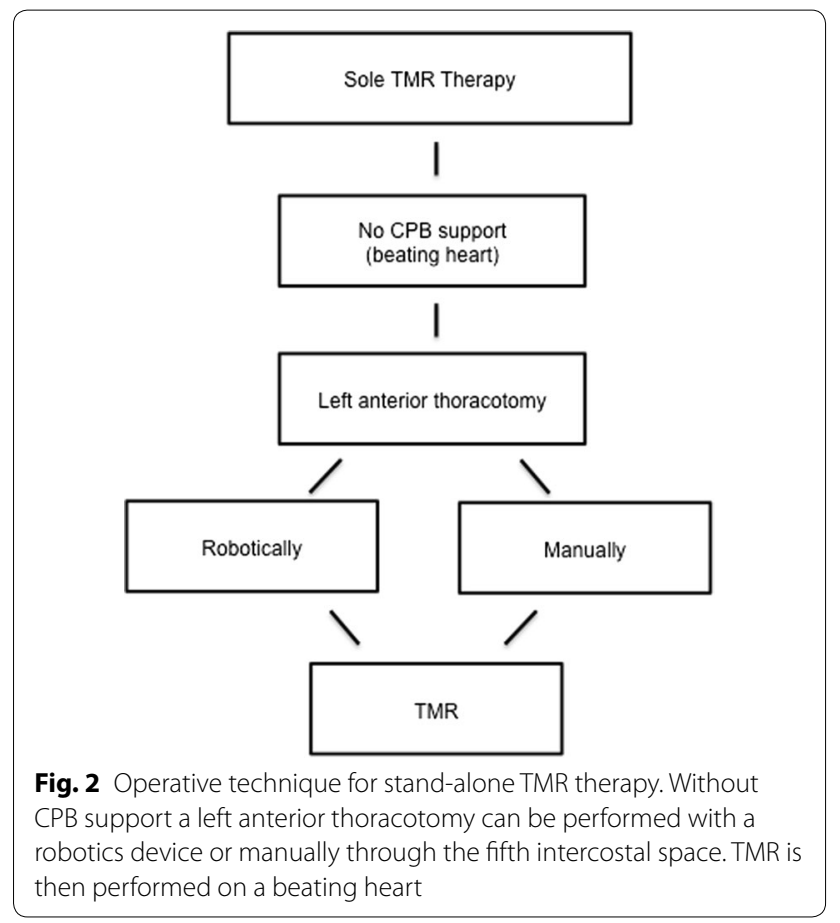

TMR channels can be created on an arrested or beating heart depending on the type of laser being employed. The carbon dioxide laser power source is only used on a beating heart with ECG synchronization while the holmium:yttrium-aluminum-garnet (Ho:YAG) TMR laser can be operated on a beating or arrested heart during bypass (Samuels et al. 2004; Horvath 2008). If the surgeon performs the procedure on a beating heart after $\mathrm{CPB}$, laser therapy can be completed following bypass grafting in order to create channels in areas that are not bypassable via grafts or that may provide inadequate blood supply. However if laser therapy is performed before bypass grafting and CPB (Frazier et al. 2004), initially bleeding can be controlled and will subside by the time surgery is complete (Samuels et al. 2004). In addition, TMR therapy can be employed after the CABG procedure, while remaining on bypass with a beating heart (Ak et al. 2009). In this setup the patient can be placed on partial $\mathrm{CPB}$, allowing for increased left ventricular filling and better tactile and auditory responses during channel creation. Lastly, if CPB support is used CABG and TMR can be performed in either order on a still heart, avoiding ventricular arrhythmias and controlling excessive channel bleeding (Samuels et al. 2004).

\section{Types of laser devices}

There are two main types of TMR lasers that are currently approved for surgical use, the carbon dioxide $\left(\mathrm{CO}_{2}\right)$ and the holmium:yttrium-aluminum-garnet 


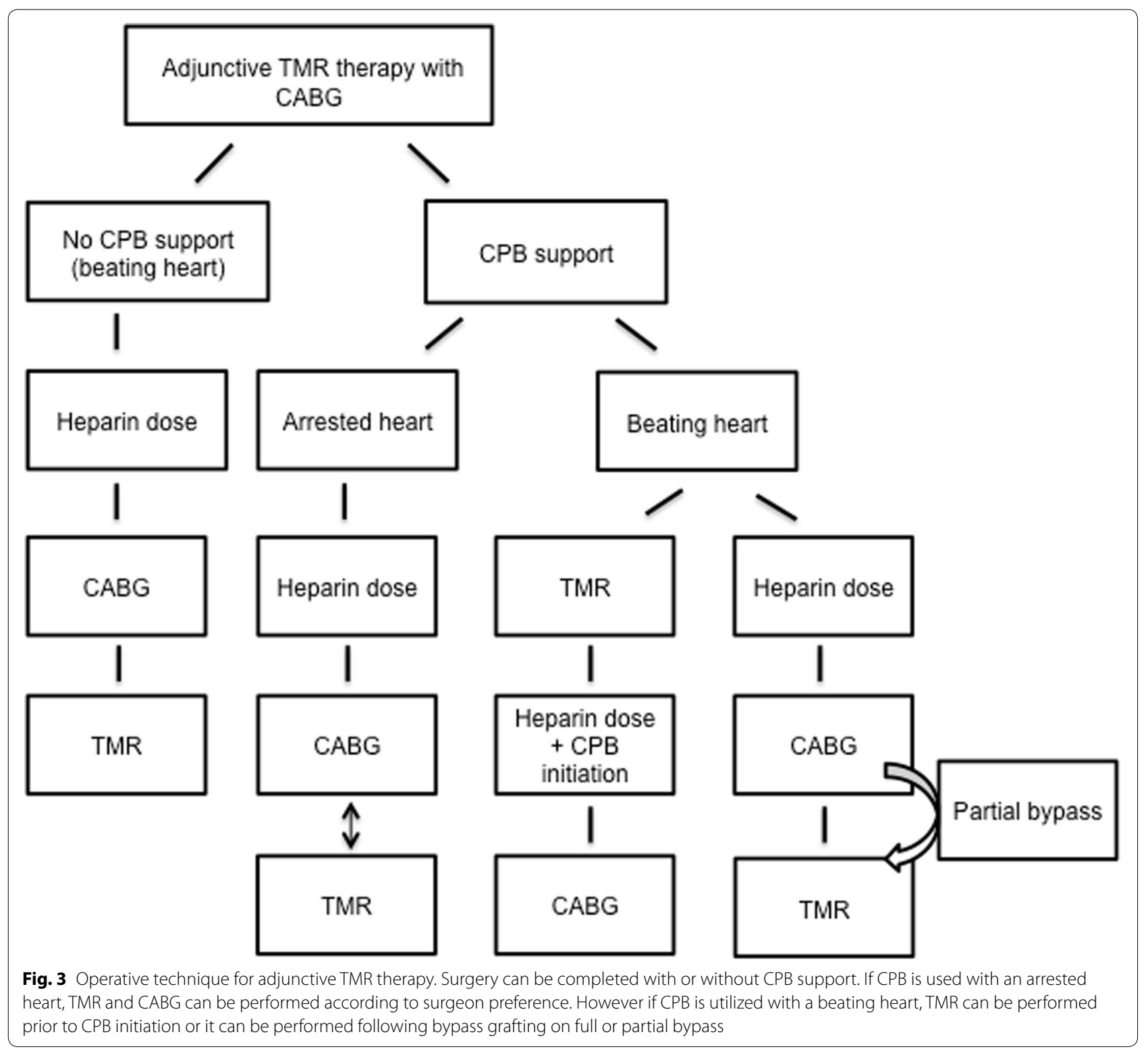

(Ho:YAG) laser system (Allen et al. 2008; Horvath 2008). Both create $1 \mathrm{~mm}$ wide channels within the myocardium that traverse the ventricular wall (Deckelbaum 1994). The $\mathrm{CO}_{2}$ laser system uses carbon dioxide gas excitation to generate infrared light and ablate surrounding tissue. Since the $\mathrm{CO}_{2}$ laser can only be delivered to a beating heart, the laser should be pulsed when the heart is quiescent or when it is electrically minimally active, to reduce the risk of arrhythmias (Samuels et al. 2004). This state corresponds to the time lapse between the $\mathrm{R}$ and $\mathrm{T}$ wave of an ECG rhythm. By avoiding laser pulsation during myocardial contraction, the $\mathrm{CO}_{2}$ laser prevents interruption of electrical signaling within the heart, increases laser accuracy and prevents laser firing to non-targeted areas of the myocardium, ultimately reducing the risk of fibrillation (Rudko and Linhares 1992). Once the laser is deployed in a single pulse, the lased energy is transmitted through the myocardial tissue and dissipated within the ventricular blood, preventing excessive thermal injury to surrounding tissue. The $\mathrm{CO}_{2}$ laser can deliver $800 \mathrm{~W}$ in one pulse lasting from 1 to $99 \mathrm{~ms}$ at energies of $8-80 \mathrm{~J}$ (Allen et al. 2008).

In contrast, the Ho:YAG laser system can deliver $7 \mathrm{~W}$ per pulse with five pulses being delivered per second to a beating or non-beating heart (Allen et al. 2008; Horvath 2008). Unlike the $\mathrm{CO}_{2}$ laser, the Ho:YAG laser delivers 
solid-state holmium:YAG through a fiber optic bundle with pulsation. Channels are placed one centimeter apart and are pulsed on the anterior, lateral, and inferior walls of the left ventricle (Gowdak et al. 2008). Typically 10-20 pulses are necessary to achieve successful penetration via tactile and auditory feedback (Samuels et al. 2004; Horvath 2008).

\section{TMR mechanisms of action and kinetics}

There are 3 competing mechanisms considered to be the source of improved myocardial oxygenation, angina relief and cardiovascular function. The first mechanism focuses on the mechanical perturbations or channels that are created within the myocardium. Termed the patent channel theory, historically this model postulates that TMR creates open conduits that provide the surrounding ischemic myocardium with nutrients and oxygen, acting as sinuses that have the potential to communicate with neighboring cardiac capillary beds. However, this theory has been received with much controversy, as studies show variable channel patency at various time intervals. Hardy et al. (1987) reported channel patency in female puppies for 2 weeks using the $\mathrm{CO}_{2}$ laser as compared to a $48 \mathrm{~h}$ patency time using a simple needle puncture as a control. Alternatively channel patency has been observed in humans for at least 3 months post mortem via histological measures (Cooley et al. 1994). Although this theory received support early on in TMR development, it has currently been rejected. Acutely, blood flow through lased channels stops momentarily and histology stains display early postoperative clot formation (Mueller et al. 1999).

A model focusing on the denervation of the myocardium has attained increased acceptance as a probable explanation for the short term effects noted after TMR therapy and for the decline in angina score following laser intervention. TMR is thought to disrupt the sympathetic afferent nerve fibers within the myocardium, therefore interrupting pain signaling (Allen et al. 2008). Sympathetic denervation was observed in 6 out of 8 TMR patients with an average increase in sympathetic denervation of $27.5 \pm 15.9 \%(\mathrm{p}=0.03)$ within 2 months of treatment (Al-Sheikh et al. 1999). The denervation hypothesis appears to be responsible for the acute effects of TMR, resulting in pain cessation and angina relief almost immediately following surgery. Cardiac nociceptors and afferent fibers are located on the superficial layer of the myocardium, allowing for communication with the brain. Since these receptors are located topically they are easily accessible by the TMR laser. Further examination of the denervation theory suggests that efferent fibers may be denervated following laser therapy. As the active sites of norepinephrine production, denervating these areas would provide $\beta$-blockade and thus reduced inotropic support, leading to decreased oxygen consumption and angina relief (Cardarelli 2006).

Since denervation provides a plausible explanation for short-term angina relief, a secondary mechanism must be accountable for the long-term effects associated with TMR. Many studies have reported increased vascular density post-TMR treatment suggesting that this laser therapy can induce angiogenesis (Fig. 4). If so, such a theory could explain the increase in myocardial perfusion that is observed following laser therapy, especially since the patent channel theory is currently being debated. Histological samples taken from deceased patients indicated the presence of necrotic tissue and inflammation at days 3 and 16. However, at day 150 fibrous scarring and increased capillary networks were seen (Gassler et al. 1997). Interestingly, this data demonstrated that injury within the myocardium can increase blood flow and that a certain degree of thermal injury is required to induce this flow. This implies that vascular growth is mediated by an inflammatory response in lased regions of the myocardium. Furthermore, the response is specific to thermal-induced laser energy and/or wavelengths, as

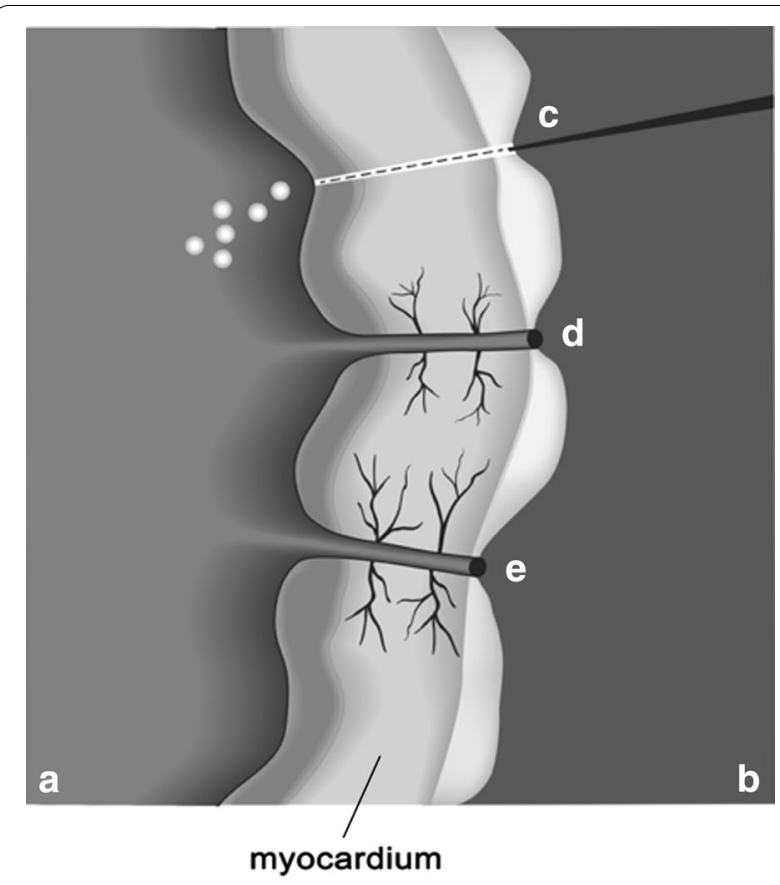

Fig. 4 Promotion of angiogenesis. A cross section of myocardium during channel creation with a TMR laser is shown and the interface between the inner (a) and outer (b) surface of the heart is depicted. The path of channel formation with the laser is depicted in $c$, with steam bubbles arising on the blood side due to heat generation during lasing. Clot formation and angiogenesis are shown at the site of the channel $(d)$ and $e$ as angiogenesis continues to be stimulated over time 
increased myocardial flow and neovascularization has consistently been observed in laser systems that employ tissue injury as compared to those that do not, such as sham or excimer lasers (Hughes et al. 2000). Therefore, it is the inflammatory-vasculogenic mechanisms that are responsible for the increased vascular network that accompanies TMR therapy.

\section{In vivo stand alone therapy}

Individuals who have a history of multiple percutaneous or surgical procedures and who present with severe diffuse CAD fall into the category of stand-alone therapy and do not meet the criteria for further PCI's or surgical interventions. The benefits of this therapeutic option have shown promising results over conventional medical management treatments. A study completed in 1999 followed 275 patients with class IV refractory angina for 2 years (Allen et al. 1999). These patients were not eligible for PCIs or CABG procedures and were thus partitioned into a group receiving TMR therapy followed by medical management or medical therapy alone. Although survival estimates for both groups were similar, those that received TMR had an increased improvement in angina relief, higher freedom from cardiac events (i.e. arrhythmia, myocardial infraction, or congestive heart failure), decreased re-hospitalizations due to cardiac events, increased quality of life scores and increased exercise tolerance stress tests (Allen et al. 1999).

The positive results found in this study prompted other retrospective and prospective studies to be completed. Collectively, these studies have examined various endpoints including operative mortality, long-term survival, angina relief, quality of life and exercise testing. After following individuals for 5 years, Allen et al. (2004) observed a decrease of two or more angina classes in $88 \%$ of TMR patients as opposed to $44 \%$ in medically managed patients $(\mathrm{p}<0.001)$. In addition, the average mortality rate after 1 year was determined as $8 \%$ for TMR patients and $13 \%$ for medically managed patients $(\mathrm{p}=0.03)$. Consequently, the observed decrease in angina relief appears to be sustained beyond a single year with promising mortality rates in those treated with laser therapy.

Despite the convincing results found in decreased angina and mortality, the debate over whether TMR therapy augments LV function, in particular LVEF and myocardial perfusion, continues to ensue with inconsistent evidence. While some groups report enhanced perfusion and hemodynamic function (via blood flow and cardiac output respectively) following laser therapy (Atluri et al. 2008) others have disregarded this notion. Tasse and Arora (2007) summarized two studies where there were no significant differences in perfusion between TMR versus medical therapy groups following SPECT or dypiridamole-thallium stress testing. Conversely, they also reported an alternate study which observed a decrease in ischemia at 3, 6, and 12 months in TMR patients, compared to an increase in ischemia in patients receiving medical treatment alone, at the same time intervals (Tasse and Arora 2007). Further comparison of LVEF from different studies by the same authors indicated no significant change after 1 year in LVEF for TMR treated groups as compared to controls in one study and a significant decrease in LVEF by $3 \%$ in another TMR group versus control study (Tasse and Arora 2007). Despite the conflicting data surrounding ventricular function, clear evidence supports the finding that patients receiving TMR typically require decreased drug therapy, in particular short acting nitrates, whereby the number of sublingual nitrates taken per month was reduced from $22.1 \pm 30.4$ to $1.4 \pm 3.9 ; \mathrm{p}<0.001$ (Reyes et al. 2010; Dallan et al. 2008; Gowdak et al. 2005). Decreased cardiac hospitalizations were noted at 12 months following laser treatment, averaging $61 \%$ versus $31 \%(\mathrm{p}<0.001)$, compared to medically managed patients (Tasse and Arora 2007).

\section{TMR therapy as an adjunct to surgical procedures}

Another option for patients with diffuse CAD is to undergo a $C A B G$ procedure in order to obtain partial revascularization, and to supplement non-vascularized regions with TMR. 1 year survival rates have been reportedly higher for CABG and TMR therapies as opposed to CABG alone (95 versus $89 \%, \mathrm{p}=0.05$ ) (Allen et al. 2000). In addition, there have been no increased operative mortality rates associated with adjunctive therapy compared to sole CABG treatment (1.5 versus $7.6 \%$ respectively, $p=0.02$ ) (Allen et al. 2000) and there have been significant decreases reported in 30 days mortality rates (13 versus $28 \%, \mathrm{p}=0.021$ ) (Frazier et al. 2004). More importantly, studies have demonstrated that using TMR in combination with $C A B G$ has led to decreased repeat revascularizations (0 dual therapy versus $24 \%$ CABG alone, $\mathrm{p}<0.05$ ) (Frazier et al. 2004) and significantly reduced inotropic support post-operatively (Allen et al. 2000). From these studies it has become evident that CABG plus TMR therapy is beneficial over sole CABG treatment since it provides increased angina relief and appears to reduce repeat revascularizations, as well as associated cardiac adverse events.

The question of whether the type of laser used is of importance in these procedures and whether surgical centers are choosing to include laser therapy within their scope of practice, has been evaluated by Tavris et al. (2012). They investigated 435 cardiothoracic hospitals within the United States over the course of 6 years, examining 15,386 patients. They categorized individuals 
into two procedure groups: those receiving TMR therapy alone, and those receiving TMR with CABG. They also subdivided these groups according to the type of laser (either $\mathrm{CO}_{2}$ or Ho:YAG) utilized to determine if there are any significant short or long term effects between laser devices. For TMR therapy performed in isolation or in combination with CABG, both lasers exhibited negligible long-term ( $>5$ years) differences in morbidity and mortality rates. However, short-term results indicated minor odds of morbidity, mortality, and operative mortality with the $\mathrm{CO}_{2}$ laser, owing to increased ventilation times. Additionally, short term results for adjunctive therapy reported increased incidences of acute renal failure, deep sternal wound infection, and operative mortality rates for the Ho:YAG laser, but decreased reoperation rates due to bleeding complications (Tavris et al. 2012).

Overall, this data demonstrates that there were no differences in the long-term effects between the two devices, however the Ho:YAG laser appeared to have increases in short-term consequences following dual therapy. It has been previously reported that the Ho:YAG laser introduces increased thermoacoustics (Fisher et al. 1997), thermal injury (Kitade et al. 1999) and tissue tearing (Genyk et al. 2000) to the surrounding muscle. However, it has also been argued that despite increased myocardial damage, it is this damage itself that is paradoxically responsible for the repair and remodeling of ischemic myocardium. Despite these observed repair mechanisms, Estvold and colleagues argued that increased fibrosis associated with the Ho:YAG device led to decreased improvements in ventricular wall thickening and function compared to the $\mathrm{CO}_{2}$ laser system (Estvold et al. 2010). Therefore, debate still exists over the extent of injury incurred by these laser devices and their subsequent effects on cardiac function.

\section{Stem cell treatment with TMR therapy in an infarcted myocardium}

The use of stem cells to treat damaged, ischemic zones within an infarcted myocardium has been explored extensively. Nascent cardiac stem cells residing in the myocardium are in limited supply, short lived and rely on immunosuppression-therefore, they can only offer minimal intrinsic regenerative capabilities for patients (Chou et al. 2014). Even though TMR is thought to induce signaling via myocardial injury and inflammation, the quantity and duration of native stem cell homing has been heavily debated. The use of injected stem cells is thought to overcome this hurdle and aid in cardiac repair post-myocardial infarction. Mesenchymal stem cell therapy as a treatment for myocardial pathology is of particular interest due to its regenerative properties aiding in heart failure treatment. The idea that such stem cells or partially differentiated stem cells can be delivered into hearts to restore function is an appealing notion since these cells possess high yields, are multipotent and play a critical role in myocardial repair (Hare et al. 2009; Dinsmore and Dib 2008; Chou et al. 2014; Nagaya et al. 2004). They have displayed significant contributions in myocardial recovery through mechanisms such as transdifferentiation, paracrine release, stimulation of native cardiac stem cells, and inflammatory control (Chou et al. 2014). Although the current paradigm for stem cell therapy focuses on their potential to differentiate into cardiomyocytes and promote cardiac repair and regeneration (Rangappa et al. 2003; Madonna et al. 2009), it has been difficult to demonstrate persistence and biodistribution of stem cells (Spiegelstein et al. 2007). Injection of these cells into the myocardium has exhibited suboptimal retention rates, reportedly ranging from 2.6 to $11.3 \%$ (Hou et al. 2005; Dib et al. 2011). The quick clearance of injected stem cells has been deemed a consequence of myocardial contraction, lymphatic and venous drainage (Richardson et al. 2013) and the hostile nature of an ischemic myocardium (Richardson et al. 2013; Reinecke et al. 1999; Robey et al. 2008; Abdelwahid et al. 2015). This limiting factor in myocardial repair is of significance since successful cell therapy is dependent upon cell homing, engraftment, and survival within the scarred myocardial tissue (Horvath et al. 2005; Richardson et al. 2013). The use of TMR with stem cell therapy could provide a promising solution to this problem and aid in stem cell homing to injured sites.

It is proposed that the inflammatory response imposed by lased thermal injury may be responsible for increased cell homing and engraftment (Shahzad et al. 2012; Patel et al. 2007) as well as angiogenesis (Hughes et al. 2000). Preliminary porcine and murine research has indicated that pretreatment of an infarcted myocardium with TMR therapy significantly enhances mesenchymal stem cell (MSC) engraftment (Patel et al. 2007; Spiegelstein et al. 2007). This engraftment can further be heightened by MSC transfection with vascular endothelial growth factors (VEGF), basic fibroblast growth factors (bFGF), and insulin-like growth factors $(70 \pm 26 \%$ survival of transfected cells with TMR compared to $47 \pm 18 \%$ survival of non-transfected BMSC with TMR, $\mathrm{p}<0.05)$. Transfected cells with laser therapy also experience an increase in vascular density as compared to TMR alone as early as 3 days following injections (Spiegelstein et al. 2007). The success of growth factor mediated repair was further explored by the use of recombinant human basic fibroblastic growth factors (rhFGF-2) and adenoviral fibroblast growth factors-2 (AdFGF-2) with remarkable results in an infarcted porcine model (Horvath et al. 2005; Lutter et al. 2002). Both demonstrated increased contractility 
and angiogenesis, with an $89 \%$ contractility improvement in the AdFGF-2+TMR group compared to either AdFGF-2 or TMR alone, $\mathrm{p}=0.001$ via cine MRI (Horvath et al. 2005). Thus, dual growth factor and laser therapy may prove to be effective in candidates with ischemic myocardium undergoing CABG or TMR therapy.

The mechanism(s) underlying the reparative effects of TMR and cell therapy are still heavily debated. It could be that increased perfusion via channel conduits increases cell implantation, prior to eventual channel closure, thus allowing for improved engraftment and angiogenesis. Furthermore the release of pro-survival cytokines (Spiegelstein et al. 2007) or pro-angiogenic growth factors such as FGF-2 (Patel et al. 2007), from inflamed zones may warrant enhanced cell transplantation survival. Current findings also suggest that injection of MSC may mobilize endothelial progenitor cells (EPC) to infarcted zones, aiding in the induction of angiogenesis and the reparative effect noted with TMR (Shahzad et al. 2012). Atluri et al. (2008) demonstrated that sole TMR therapy in a porcine model was able to increase the amount of circulating EPCs post treatment due to the upregulation of NFkB (42.6 \pm 27 intensity units versus $591.6 \pm 383$ intensity units, $\mathrm{p}=0.03$ ). NFkB is a potent chemokine and mediator in vasculogenesis, known to excite various vasculogenic agents (VEGF and bFGF). It is thought that it may be responsible for the increase in EPCs within the infarcted myocardium, aiding in vasculogenesis and myocardial perfusion. Moreover, TMR therapy has been shown to upregulate angiopoitein-1 expression $(0 \pm 0$ intensity units vs. $241 \pm 87$ intensity units, $\mathrm{p}=0.003)$, which has been strongly associated with vasculogenesis and the maturation of vessels (Atluri et al. 2008). Therefore, together with stem cell injection, it is quite evident that both laser and cell therapies can offer synergistic angiogenic effects within scarred, infarcted myocardium.

Clinical assessments following autologous intramyocardial injection of MSC and TMR therapy have yielded promising results for patients with limited therapeutic options. Reports of decreased angina classification of at least two functional classes (from $3.7 \pm 0.2$ to $1.3 \pm 0.2$, $\mathrm{p}<0.0001$ ) (Dallan et al. 2008) and improved quality of life have been unanimous amongst all case reports (Reyes et al. 2010; Gowdak et al. 2008; Dallan et al. 2008; Konstanty-Kalandyk et al. 2013). Evaluation of ischemic score and LV thickening via MRI have also demonstrated significant improvements 6 months post treatment, with an average decrease in ischemic score from $1.56 \pm 0.09$ to $0.93 \pm 0.10(\mathrm{p}=0.01$ ) (Gowdak et al. 2008; Dallan et al. 2008; Gowdak et al. 2005). Ischemic scores, measured with MRI during pharmacological stress with dypiridamole, have been used as determinants of myocardial perfusion, while LV thickening has been utilized as a predictor of contractility following therapy. KonstantyKalandyk et al. (2013) further examined these parameters concluding that LV segments treated with bone marrow derived MSC + TMR (BMLR) have increased thickening compared to baseline $(53.0 \pm 7.5$ vs. $45.0 \pm 9.5 \%$; $\mathrm{p}=0.06$ ) at 1 year post-treatment (Konstanty-Kalandyk et al. 2013). More importantly, they reported that in all but one patient, LV regions treated with BMLR did not demonstrate new infarctions, whereas regions left unattended by BMLR revealed new or enhanced infarcted areas. Ejection fractions, measured pre- and post-treatment, demonstrated conflicting results, concurrent with numerous other study findings. Although Gowdak et al. reported an LVEF improvement from 27 to $43 \%$ in their case report, other institutions have dismissed the idea that TMR and/or cell therapy has an effect on LVEF (Allen et al. 1999; Patel et al. 2007; Klein et al. 2004; Gowdak et al. 2005).

However more recent outcomes in clinical trials have yielded interesting results for sole stem cell therapy. In a meta-analysis published by Kandala et al. (2013), the effect of bone-marrow derived stem cells on ischemic cardiomyopathy was analyzed. By examining over 519 patients and 10 clinical trials they determined that LVEF increased by $4.48 \%(\mathrm{p}=0.0001)$ within 6 months. Furthermore they reported superior effects on LVEF with intramyocardial injections as opposed to intracoronary injections $(5.13 \%, \mathrm{p}<0.0001$ versus $2.32 \%, \mathrm{p}=0.3$ respectively). Other study findings included significant reductions in LV end-diastolic and end-systolic volumes within stem cell treated patients (Kandala et al. 2013). These results were further supported in a larger metaanalysis examining over 31 randomized controlled trials and 1521 patients with ischemic and non-ischemic cardiomyopathy (Fisher et al. 2015). Administration of any autologous cell therapy via any route was included in the study criteria. Primary endpoints revealed a significant reduction in mortality $\geq 12$ months with patients who received cell therapy alone $(\mathrm{p}<0.0001)$ as well as significant decreases in re-hospitalization rates among stem cell patients with heart failure $(\mathrm{p}=0.002)$. No significance was noted between control and treatments groups in regards to long-term follow-up of arrhythmias $(p=0.61)$, however significant changes were seen in long-term follow-up of LVEF. Mean increase for LVEF was reported as $4.02 \%(\mathrm{p}=0.007)$ and $3.57 \%(\mathrm{p}=0.03)$ for ischemic heart failure patients alone. Secondary outcomes displayed significant improvements in exercise tolerance $(\mathrm{p}=0.02)$ and quality of life $(\mathrm{p}=0.0003)$. Myocardial perfusion, however, showed conflicting results. Four trials reported significant increases in perfusion while three trials found no significance. These findings 
can suggest two points. One, that stem cell therapy alone may be sufficient enough to provide therapeutic effects in patients suffering from heart failure. It may be that there short-term engraftment can suffice in providing patients with long-term benefits. Two, that TMR may augment the short-comings of stem cell therapy and provide increased longevity of stem cell engraftment and therefore increased therapeutic effects. An example of this would include studies which report increased myocardial perfusion following TMR (March 1999), and studies which showcase a decrease of two or more angina classifications post TMR (Leon et al. 2005).

\section{Cost analysis}

The decrease in cardiac hospitalizations associated with TMR has not only benefited patient outcomes but it has also been associated with significant hospital cost reductions. The average cost for a patient admitted for angina is estimated to be $\$ 3000$ per visit. Clinical trials indicate that TMR can reduce these visits by as much as $80 \%$. Campbell et al. (2001) analyzed 188 patients receiving TMR therapy or medical management at a single UK centre. The total cost for TMR therapy was quoted as $\$ 16,500$ per patient, with $\$ 3480$ of that cost coming from $\mathrm{CO}_{2}$ laser equipment use and $\$ 8630$ from inpatient resource use. Alternatively the cost for medical management alone was $\$ 3720$ per patient with $\$ 2900$ coming from inpatient and outpatient episodes (Campbell et al. 2001). Although this paper concluded that TMR plus medical management is not cost effective from a UK National Health Service perspective, the periodical Cost Management in Cardiac Care (1998) argued that TMR has decreased costs of hospitalization time and transfusion rates. Furthermore the average cost of bypass surgery is $\$ 40,000$ and an angioplasty with a stent can amount to $\$ 20,000$ with possible need for repetition. On the other hand TMR alone costs an average of $\$ 25,000$ with quicker recoveries and shorter hospital stays as compared to complete bypass surgery. Although TMR may reduce expenses in the long run versus medical management, this cost-benefit analysis must be closely considered when performing adjunctive CABG procedures and stem cell therapies. A more recent multi-centre study analyzed the cost of mobilizing, harvesting and cryopreserving autologous blood progenitor cells (Mishra et al. 2005). Although the intent of use for these cells was to treat malignant lymphomas and multiple myeloma's, the study highlights expenses associated with autologous cell delivery. The mean cost of processing stem cells amounted to $\$ 6544$ per patient. The majority of this expenditure came from hospitalization, growth factors and cryopreservation. Therefore patients considering stem cell therapy should be aware of additional costs associated with this treatment.

\section{Future research}

Laser therapy was first employed for use with patients who could not be revascularized, offering angiogenic properties to ischemic myocardium. Currently, this therapy has been extended to treat scarred, ischemic myocardium with the addition of cell therapy. It is this hybrid treatment that can offer reparative and regenerative properties to injured myocardial tissue in addition to angiogenesis or denervation alone. Therefore, the direction of future research depends on the ability to increase cell homing and engraftment of these cells in order to allow proper repair and function of diseased hearts. Thus far, the literature has reported the use of MSC with laser therapy and their beneficial effects. Due to positive feedback from this dual therapy within the clinical setting it is now important to delineate the precise mechanisms responsible for the aforementioned improvements in cardiac function and determine whether these effects can sustain long-term benefits for patients. Clearly, an alteration in the ischemic microenvironment of the myocardium via laser energy is allowing for increased cell engraftment and survival. Therefore, the attempt to understand the clinical reverberations of this hybrid therapy should focus on the molecular and metabolic interactions occurring at the cellular level.

\section{Conclusion}

TMR has emerged as a promising therapeutic option for patients suffering with diffuse coronary artery disease. The use of TMR within this subgroup has demonstrated many beneficial effects, not only in the quality of life but also in the repair and remodeling of myocardial tissue. To date, this therapeutic option has exhibited encouraging improvements within an ischemic heart model, with angiogenesis acting as the main contributor to the longterm effects noted in patients. Considering that the average amount of tissue affected by this laser treatment is $2 \mathrm{~g}$ of muscle (using the Ho:YAG device with 40 lased channels), which corresponds to approximately $1.7-3.2 \%$ of left ventricular mass (Dallan et al. 2008), it is remarkable how this therapy can produce significant angina relief and angiogenesis. The use of cell therapy in conjunction with TMR heightens this response and provides another avenue by which an ischemic myocardium can be revascularized. The future of TMR therapy and research hinges on its collaboration with cell therapies in order to further enhance myocardial repair, regeneration and revascularization.

\section{Abbreviations}

CAD: coronary artery disease; TMR: transmyocardial revascularization; CABG: coronary artery bypass grafting; $\mathrm{PCl}$ : percutaneous coronary interventions; CPB: cardiopulmonary bypass; HF: heart failure. 


\section{Authors' contributions}

II conceived of the study, carried out the design, coordination and full writeup of the manuscript. RKW participated in the design, layout and editing of the manuscript. DFL participated in the design, scope and editing of the manuscript. ASF participated in the writing, editing and figure design of the manuscript. RBR participated in the editing, design and scope of manuscript. SG participated in the writing, design, editing and final draft of the manuscript. ZK conceived of the study, participated in study design, layout, editing and drafting the manuscript. All authors read and approved the final manuscript.

\section{Author details \\ 1 Department of Pharmacology, University of Arizona College of Medicine, Tucson, AZ, USA. ${ }^{2}$ Department of Surgery, Division of Cardiothoracic Surgery, University of Arizona College of Medicine, P.O. Box 245071, 1501N. Campbell Avenue, Tucson, AZ 85724-5071, USA. ${ }^{3}$ Department of Physiological Sciences, University of Arizona College of Medicine, Tucson, AZ, USA. ${ }^{4}$ Department of Cellular and Molecular Medicine, University of Arizona College of Medicine, Tucson, AZ, USA. ${ }^{5}$ Research and Development, Cryolife, Inc., Kennesaw, GA, USA. ${ }^{6}$ Banner University Medical Center, 1501N. Campbell Avenue, Room 4302A, Tucson, AZ 85724, USA. ${ }^{7}$ Medical Research Building, 1656 E. Mabel St, Rm 120, Tucson, AZ, USA.}

\section{Acknowledgements}

This review was supported by the staff and students in the Perfusion Department at the University of Arizona Medical Center and by the members of the Khalpey Cardiothoracic Surgery Laboratory.

\section{Competing interests}

The author (Zain Khalpey) of this publication has (i) received research support from Amnio Technology, LLC, (ii) held stock in Amnio Technology, LLC, and (ii) served as a paid consultant for Amnio Technology, LLC within the twenty-four month period preceding this publication. The terms of this arrangement have been reviewed and appropriately managed by the University of Arizona in accordance with its conflict of interest policies. The authors wish to declare that author Steven Goldstein may have a perceived conflict of interest as he has an ongoing financial relationship with CryoLife, Inc., which manufactures CardioGenesis cardiac laser therapy product line.

\section{Funding}

This work was not supported by any funding agency in the public, commercial, or not-for-profit sectors.

Received: 8 October 2015 Accepted: 17 May 2016

Published online: 16 June 2016

\section{References}

Abdelwahid E, Kalvelyte A, Stulpinas A, de Carvalho KAT, Guarita-Souza LC, Foldes $G$ (2015) Stem cell death and survival in heart regeneration and repair. Apoptosis. doi:10.1007/s10495-015-1203-4

Ak K, Isbir S, Gürsu O, Arsan S (2009) The effect of transmyocardial laser revascularization on anginal symptoms and clinical results in patients with incomplete surgical revascularization. Türk Kardiyoloji Derneği Arşivi : Türk Kardiyoloji Derneğinin Yayın Organıdır 37(4):246-252

Allen KB, Dowling RD, Fudge TL, Schoettle GP, Selinger SL, Gangahar DM, Angell WW, Petracek MR, Shaar CJ, O'Neill WW (1999) Comparison of transmyocardial revascularization with medical therapy in patients with refractory angina. N Engl J Med 341(14):1029-1036. doi:10.1056/ NEJM199909303411403

Allen KB, Dowling RD, DelRossi AJ, Realyvasques F, Lefrak EA, Pfeffer TA, Fudge TL et al (2000) Transmyocardial laser revascularization combined with coronary artery bypass grafting: a multicenter, blinded, prospective, randomized, controlled trial. J Thorac Cardiovasc Surg 119(3):540-549

Allen KB, Dowling RD, Schuch DR, Pfeffer TA, Marra S, Lefrak EA, Fudge TL, Mostovych M, Szentpetery S, Saha SP, Murphy D, Dennis H (2004) Adjunctive transmyocardial revascularization: five-year follow-up of a prospective, randomized trial. Ann Thorac Surg 78(2):458-465. doi:10.1016/j. athoracsur.2004.04.049
Allen KB, Kelly J, Borkon AM, Stuart RS, Daon E, Pak AF, Zorn GL, Haines M (2008) Transmyocardial laser revascularization: from randomized trials to clinical practice. A review of techniques, evidence-based outcomes, and future directions. Anesthesiol Clin 26(3):501-519. doi:10.1016/j. anclin.2008.04.001

Al-Sheikh T, Allen KB, Straka SP, Heimansohn DA, Fain RL, Hutchins GD, Sawada SG, Zipes DP, Engelstein ED (1999) Cardiac sympathetic denervation after transmyocardial laser revascularization. Circulation 100(2):135-140

Andréll P, Ekre O, Grip L, Währborg P, Albertsson P, Eliasson T, Jeppsson A, Mannheimer C (2011) Fatality, morbidity and quality of life in patients with refractory angina pectoris. Int J Cardiol 147(3):377-382. doi:10.1016/j. ijcard.2009.09.538

Atluri P, Panlilio CM, Liao GP, Suarez EE, McCormick RC, Hiesinger W, Cohen JE et al (2008) Transmyocardial revascularization to enhance myocardial vasculogenesis and hemodynamic function. J Thorac Cardiovasc Surg 135(2):283-291. doi:10.1016/j.jtcvs.2007.09.043 (291.e1; discussion 291)

Campbell HE, Tait S, Buxton MJ, Sharples LD, Caine N, Schofield PM, Wallwork $J$ (2001) A UK trial-based cost-utility analysis of transmyocardial laser revascularization compared to continued medical therapy for treatment of refractory angina pectoris. Eur J Cardiothorac Surg 20(2):312-318

Cardarelli M (2006) A proposed alternative mechanism of action for transmyocardial revascularization prefaced by a review of the accepted explanations. Tex Heart Inst J 33(4):424-426

Chou S-H, Lin S-Z, Kuo W-W, Pai P, Lin J-Y, Lai C-H, Kuo C-H, Lin K-H, Tsai F-J, Huang C-Y (2014) Mesenchymal stem cell insights: prospects in cardiovascular therapy. Cell Transplant 23(4-5):513-529. doi:10.3727/0963689 $14 \times 678436$

Cooley DA, Frazier OH, Kadipasaoglu KA, Pehlivanoglu S, Shannon RL, Angelin P (1994) Transmyocardial laser revascularization. Anatomic evidence of long-term channel patency. Tex Heart Inst J 21(3):220-224

Dallan LAO, Gowdak LH, Lisboa LAF, Schettert I, Krieger JE, Cesar LAM, de Oliveira SA, Stolf NAG (2008) Cell therapy plus transmyocardial laser revascularization: a proposed alternative procedure for refractory angina. Rev Bras Cir Cardiovasc 23(1):46-52

Deckelbaum LI (1994) Cardiovascular applications of laser technology. Lasers Surg Med 15(4):315-341

Dib N, Khawaja H, Varner S, McCarthy M, Campbell A (2011) Cell therapy for cardiovascular disease: a comparison of methods of delivery. J Cardiovasc Transl Res 4(2):177-181. doi:10.1007/s12265-010-9253-z

Dinsmore JH, Dib N (2008) Stem cells and cardiac repair: a critical analysis. J Cardiovasc Transl Res 1(1):41-54. doi:10.1007/s12265-007-9008-7

Estvold SK, Mordini F, Zhou Y, Yu ZX, Sachdev V, Arai A, Horvath KA (2010) Does laser type impact myocardial function following transmyocardial laser revascularization? Lasers Surg Med 42(10):746-751. doi:10.1002/ Ism.21012

Fisher PE, Khomoto T, DeRosa CM, Spotnitz HM, Smith CR, Burkhoff D (1997) Histologic analysis of transmyocardial channels: comparison of $\mathrm{CO}_{2}$ and holmium:YAG lasers. Ann Thorac Surg 64(2):466-472. doi:10.1016/ S0003-4975(97)00519-5

Fisher SA, Doree C, Mathur A, Martin-Rendon E (2015) Meta-analysis of cell therapy trials for patients with heart failure. Circ Res 116(8):1361-1377. doi:10.1161/CIRCRESAHA.116.304386

Frazier OH, Tuzun E, Eichstadt H, Boyce SW, Lansing AM, March RJ, Sartori M, Kadipasaoglu KA (2004) Transmyocardial laser revascularization as an adjunct to coronary artery bypass grafting: a randomized, multicenter study with 4-year follow-up. Tex Heart Inst J 31(3):231-239

Gassler N, Wintzer HO, Stubbe HM, Wullbrand A, Helmchen U (1997) Transmyocardial laser revascularization. Histological features in human nonresponder myocardium. Circulation 95(2):371-375

Genyk IA, Frenz M, Ott B, Walpoth BH, Schaffner T, Carrel TP (2000) Acute and chronic effects of transmyocardial laser revascularization in the nonischemic pig myocardium by using three laser systems. Lasers Surg Med 27(5):438-450. doi:10.1002/1096-9101(2000)27:5<438:AID-LSM1005>3.0.CO;2-3

Gowdak LHW, Schettert IT, Rochitte CE, Lisboa LAF, Dallan LAO, César LAM, Krieger JE, Ramires JAF, de Oliveira SA (2005) Cell therapy plus transmyocardial laser revascularization for refractory angina. Ann Thorac Surg 80(2):712-714. doi:10.1016/j.athoracsur.2005.04.080

Gowdak LHW, Schettert IT, Rochitte CE, Rienzo M, Lisboa LAF, Dallan LAO, César LAM, Krieger JE, Ramires JAF, de Oliveira SA (2008) Transmyocardial 
laser revascularization plus cell therapy for refractory angina. Int J Cardiol 127(2):295-297. doi:10.1016/j.ijcard.2007.05.048

Hardy RI, Bove KE, James FW, Kaplan S, Goldman L (1987) A histologic study of laser-induced transmyocardial channels. Lasers Surg Med 6(6):563-573

Hare JM, Traverse JH, Henry TD, Dib N, Strumpf RK, Schulman SP, Gerstenblith G et al (2009) A randomized, double-blind, placebo-controlled, dose-escalation study of intravenous adult human mesenchymal stem cells (prochymal) after acute myocardial infarction. J Am Coll Cardiol 54(24):2277-2286. doi:10.1016/j.jacc.2009.06.055

Horvath KA (2008) Transmyocardial laser revascularization. J Card Surg 23(3):266-276. doi:10.1111/j.1540-8191.2008.00579.x

Horvath KA, Lu CYJ, Robert E, Pierce GF, Greene R, Sosnowski BA, Doukas J (2005) Improvement of myocardial contractility in a porcine model of chronic ischemia using a combined transmyocardial revascularization and gene therapy approach. J Thorac Cardiovasc Surg 129(5):1071-1077. doi:10.1016/j.jtcvs.2004.10.017

Hou D, Youssef EA, Brinton TJ, Zhang P, Rogers P, Price ET, Yeung AC, Johnstone BH, Yock PG, March KL (2005) Radiolabeled cell distribution after intramyocardial, intracoronary, and interstitial retrograde coronary venous delivery: implications for current clinical trials. Circulation $112(9$ Suppl):1150-1156. doi:10.1161/CIRCULATIONAHA.104.526749

Hughes GC, Kypson AP, Annex BH, Yin B, St Louis JD, Biswas SS, Coleman RE et al (2000) Induction of angiogenesis after TMR: a comparison of holmium:YAG, $\mathrm{CO}_{2}$, and excimer lasers. Ann Thorac Surg 70(2):504-509

Kandala J, Upadhyay GA, Pokushalov E, Wu S, Drachman DE, Singh JP (2013) Meta-analysis of stem cell therapy in chronic ischemic cardiomyopathy. Am J Cardiol 112(2):217-225. doi:10.1016/j.amjcard.2013.03.021

Kim MC, Kini A, Sharma SK (2002) Refractory angina pectoris: mechanism and therapeutic options. J Am Coll Cardiol 39(6):923-934

Kitade T, Okada M, Tsuji Y, Nakamura M, Matoba Y (1999) Experimental investigations on relationships between myocardial damage and laser type used in transmyocardial laser revascularization (TMLR). Kobe J Med Sci 45(3-4):127-136

Klein H-M, Ghodsizad A, Borowski A, Saleh A, Draganov J, Poll L, Stoldt V et al (2004) Autologous bone marrow-derived stem cell therapy in combination with TMLR. A novel therapeutic option for endstage coronary heart disease: report on 2 cases. Heart Surg Forum 7(5):E416-E419. doi:10.1532/ HSF98.20041095

Konstanty-Kalandyk J, Piątek J, Miszalski-Jamka T, Rudziński P, Walter Z, Bartuś K, Urbańczyk-Zawadzka M, Sadowski J (2013) The combined use of transmyocardial laser revascularisation and intramyocardial injection of bone-marrow derived stem cells in patients with end-stage coronary artery disease: one year follow-up. Kardiol Pol 71(5):485-492. doi:10.5603/ KP.2013.0095

Leon MB, Kornowski R, Downey WE, Weisz G, Baim DS, Bonow RO, Hendel RC et al (2005) A blinded, randomized, placebo-controlled trial of percutaneous laser myocardial revascularization to improve angina symptoms in patients with severe coronary disease. J Am Coll Cardiol 46(10):18121819. doi:10.1016/j.jacc.2005.06.079

Lindsay MR (2003) Transmyocardial laser revascularization revisited. Crit Care Nurs Q 26(1):69-75

Lutter G, Attmann T, Heilmann C, von Samson P, von Specht B, Beyersdorf $F$ (2002) The combined use of transmyocardial laser revascularization (TMLR) and fibroblastic growth factor (FGF-2) enhances perfusion and regional contractility in chronically ischemic porcine hearts. Eur J Cardiothorac Surg 22(5):753-761

Madonna R, Geng Y-J, De Caterina R (2009) adipose tissue-derived stem cells: characterization and potential for cardiovascular repair. Arterioscler Thromb Vasc Biol 29(11):1723-1729. doi:10.1161/ATVBAHA.109.187179

March RJ (1999) Transmyocardial laser revascularization with the $\mathrm{CO}_{2}$ laser: one year results of a randomized, controlled trial. Semin Thorac Cardiovasc Surg 11(1):12-18
Mishra V, Andresen S, Brinch L, Kvaløy S, Ernst P, Lønset MK, Tangen JM et al (2005) Cost of autologous peripheral blood stem cell transplantation: the Norwegian experience from a multicenter cost study. Bone Marrow Transplant 35(12):1149-1153. doi:10.1038/sj.bmt. 1704988

Mueller XM, Tevaearai HT, Chaubert P, Genton CY, von Segesser LK (1999) Mechanism of action of transmyocardial laser revascularization (animal experiment). Schweiz Med Wochenschr 129(48):1889-1892

Nagaya N, Fujii T, Iwase T, Ohgushi H, Itoh T, Uematsu M, Yamagishi M, Mori H, Kangawa K, Kitamura S (2004) Intravenous administration of mesenchymal stem cells improves cardiac function in rats with acute myocardial infarction through angiogenesis and myogenesis. Am J Physiol Heart Circ Physiol 287(6):H2670-H2676. doi:10.1152/ajpheart.01071.2003

Patel AN, Spadaccio C, Kuzman M, Park E, Fischer DW, Stice SL, Mullangi C, Toma C (2007) Improved cell survival in infarcted myocardium using a novel combination transmyocardial laser and cell delivery system. Cell Transplant 16(9):899-905

Rangappa S, Fen C, Lee EH, Bongso A, Wei EKS (2003) Transformation of adult mesenchymal stem cells isolated from the fatty tissue into cardiomyocytes. Ann Thorac Surg 75(3):775-779

Reinecke H, Zhang M, Bartosek T, Murry CE (1999) Survival, integration, and differentiation of cardiomyocyte grafts: a study in normal and injured rat hearts. Circulation 100(2):193-202

Reyes G, Allen KB, Alvarez P, Alegre A, Aguado B, Olivera MJ, Caballero P, Rodríguez JL, Duarte J (2010) Mid term results after bone marrow laser revascularization for treating refractory angina. BMC Cardiovasc Disord 10(January):42. doi:10.1186/1471-2261-10-42

Richardson JD, Nelson AJ, Zannettino ACW, Gronthos S, Worthley SG, Psaltis PJ (2013) Optimization of the cardiovascular therapeutic properties of mesenchymal stromal/stem cells-taking the next step. Stem Cell Rev 9(3):281-302. doi:10.1007/s12015-012-9366-7

Robey TE, Saiget MK, Reinecke H, Murry CE (2008) Systems approaches to preventing transplanted cell death in cardiac repair. J Mol Cell Cardiol 45(4):567-581. doi:10.1016/j.yjmcc.2008.03.009

Rudko RI, Linhares SJ (1992) Heart-synchronized pulsed laser system. US Patent $5,125,926$

Samuels L, Emery R, Lattouf O, Grosso M, AlZeerah M, Schuch D, Wehberg K, Muehrcke D, Dowling R (2004) Transmyocardial laser therapy: a strategic approach. Heart Surg Forum 7(3):E218-E229. doi:10.1532/ HSF98.20033011

Shahzad U, Li G, Zhang Y, Yau TM (2012) Transmyocardial revascularization induces mesenchymal stem cell engraftment in infarcted hearts. Ann Thorac Surg 94(2):556-562. doi:10.1016/j.athoracsur.2012.03.048

Spiegelstein D, Kim C, Zhang Y, Li G, Weisel RD, Li R-K, Yau TM (2007) Combined transmyocardial revascularization and cell-based angiogenic gene therapy increases transplanted cell survival. Am J Physiol Heart Circ Physiol 293(6):H3311-H3316. doi:10.1152/ajpheart.00178.2007

Tasse J, Arora R (2007) Transmyocardial revascularization: peril and potential. J Cardiovasc Pharmacol Ther 12(1):44-53. doi:10.1177/1074248406297640

Tavris DR, Brennan JM, Sedrakyan A, Zhao Y, O'Brien SM, Peterson ED, Gross TP, Marinac-Dabic D, Horvath KA (2012) Long-term outcomes after transmyocardial revascularization. Ann Thorac Surg 94(5):1500-1508. doi:10.1016/j.athoracsur.2012.05.068

\section{Submit your manuscript to a SpringerOpen ${ }^{\circ}$ journal and benefit from:}

- Convenient online submission

- Rigorous peer review

- Immediate publication on acceptance

- Open access: articles freely available online

- High visibility within the field

- Retaining the copyright to your article

Submit your next manuscript at $\boldsymbol{\nabla}$ springeropen.com 